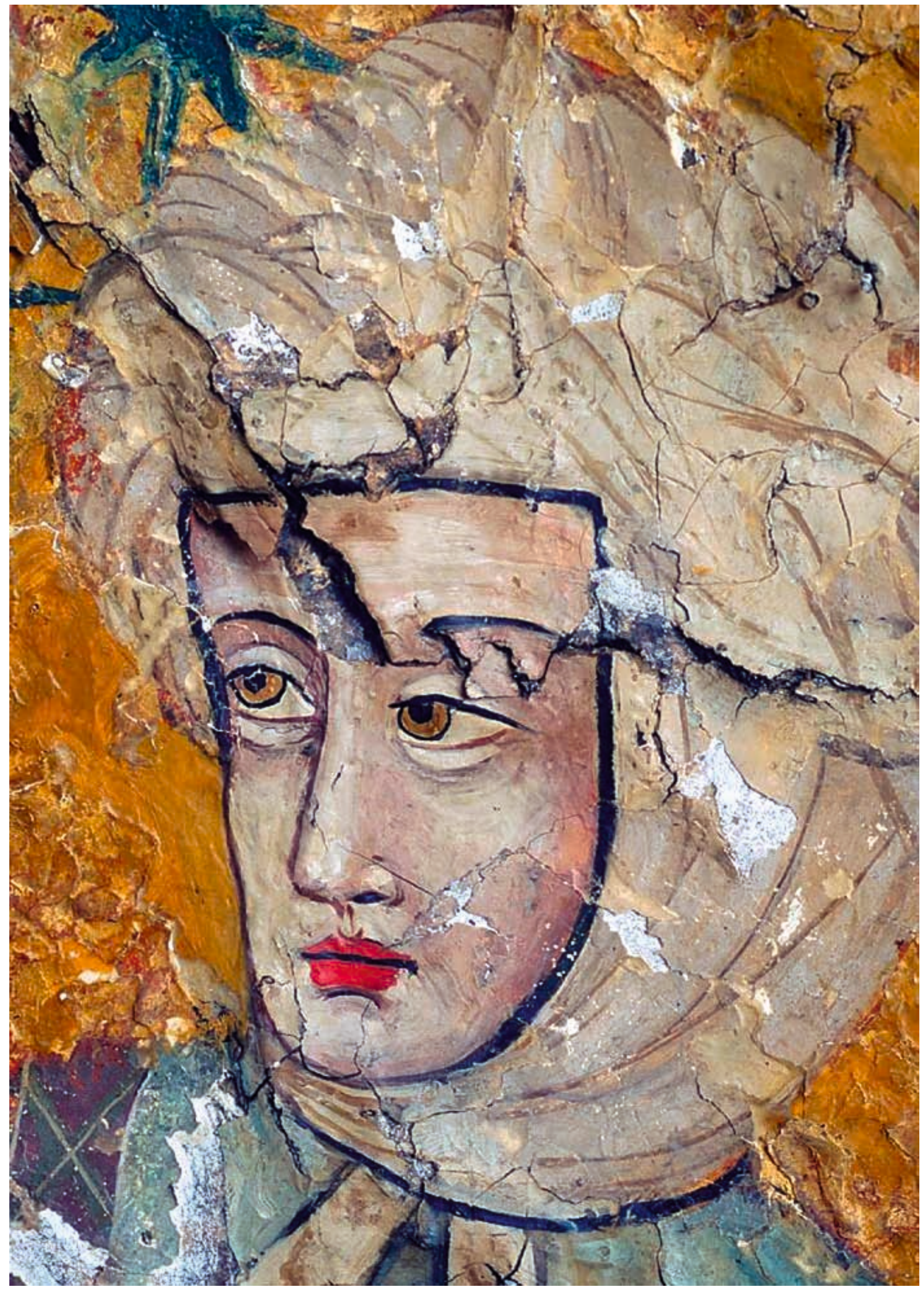




\section{Reintegración virtual de lagunas. Las pinturas de la Sala de los Reyes de la Alhambra de Granada}

María José González López y Vanessa

Martinez Calvo, Dpto. de Pintura,

U. de Sevilla

\section{Resumen}

En este artículo se expone el método seguido para articular la puesta a punto de un sistema de reintegración virtual de lagunas presentes en bienes culturales. Se evidencia su utilidad a la hora de definir la intervención; no sólo para delimitar los criterios de actuación, sino también los sistemas de reintegración más adecuados a la naturaleza, estado y necesidades conservativas y estéticas del bien, con objeto de que constituya una herramienta más de trabajo que ayude a que la decisión que se adopte por parte de los técnicos e instituciones implicadas se sustente, además de en los parámetros tradicionales, basados en el diagnóstico, en los factores de alteración y en la tecnología de tratamiento más adecuada a sus necesidades y a sus exigencias estéticas, históricas o conservativas, en la visión virtual de la imagen de la obra, tratada digitalmente, con los distintos sistemas de reintegración que actualmente se vienen aplicando en este tratamiento en bienes pictóricos o escultóricos.

Se expone paso a paso el procedimiento seguido, el software utilizado y las herramientas básicas empleadas para poder establecer el método que permita su posterior aplicación, si asi se estima, a la intervención sistemática de bienes pictóricos y escultóricos.

El estudio y desarrollo de esta metodología forman parte de uno de los distintos proyectos de intervención en el conjunto monumental en los que participa el IAPH desde enero de 2007 a petición del Patronato de la Alhambra y el Generalife (PAG), y fruto del acuerdo de colaboración existente entre ambas instituciones.

\section{Palabras clave}

Alhambra de Granada / Centro de Intervención / Conservación / Granada / Instituto Andaluz del Patrimonio Histórico / Intervención / Patrimonio mueble / Pinturas / Alhambra, Sala de los Reyes (Granada) / Reintegración de lagunas faltantes / Tratamiento digital de la imagen 


\section{INTRODUCCIÓN}

Nadie duda hoy en día que la intervención en bienes culturales se aborda desde su conocimiento previo y profundo, para lo que resulta necesario disponer de una serie de herramientas y de metodologías que nos permitan aproximarnos a los bienes desde diferentes perspectivas no exclusivas sino complementarias entre sí. Sin duda una de las herramientas más útiles, de entre las que actualmente dispone el conservador-restaurador para aproximarse al conocimiento de los bienes culturales y a su documentación, es la informática aplicada a su estudio tecnológico, a su diagnóstico y/o a su actuación.

La reintegración de lagunas se presenta, sin duda, como uno de los tratamientos propios de la restauración más comprometido por los condicionantes históricos y conservativos que, necesariamente, se deben evaluar para que su intervención no entre en conflicto con los considerandos derivados de su evolución temporal, consecuencia de las aportaciones que, fruto de su deterioro, de la moda, de las actuaciones de reparación o, simplemente, de su alteración, ha sufrido su apariencia.

El bien cultural afectado por un estado lacunar o de desgaste de su piel se manifiesta desprovisto de sus caracteristicas artísticas y cromáticas; de hecho, este estado desvirtúa su percepción interfiriendo en su apreciación, lectura y comprensión por parte del espectador, especialista o no. En este estado, las posibilidades con las que se puede abordar su reintegración son múltiples, aún cuando se respeten los criterios históricos, estéticos y conservativos, y se ejecute con las técnicas hoy dia aceptadas por los profesionales e instituciones dedicadas al patrimonio. No cabe duda de que el sistema de reintegración que se seleccione influirá decisivamente en la visión final de la obra, resulta evidente que una obra, aún respetando los principios y criterios enunciados con anterioridad, puede reintegrarse con distintos sistemas: discernible -rigatino, puntillismo, tinta plana, etc.- o mimética -invisible-, y pese a ser todos ellos válidos y aceptados por la comunidad profesional, la percepción final del bien tras su restauración puede ser muy diferente en función del sistema que se haya seleccionado y aplicado. Por lo que en la definición de este tratamiento hay que evaluar además de los factores derivados de sus necesidades conservativas, aquellos otros aspectos relacionados con los criterios y la técnica de reintegración, o la influencia que ejerce el sistema de reintegración seleccionado en la presentación estética final de la obra y en su lectura formal, sin olvidarnos de las consideraciones materiales, temporales y económicas que implica su ejecución práctica; hoy dia nadie pone en duda que este tratamiento es uno de los más costosos por el número de horas que requiere y el coste del operador que lo ejecuta.

Una vez que se ha adoptado el criterio de intervenir estéticamente un bien cultural, consideramos que la toma de decisión podría verse simplificada si los técnicos y agentes implicados dispusiesen de una herramienta visual, factible, cómoda, senci-
Ila, inocua, reproducible, de reiterada aplicación y fácil de ejecutar, que permitiese visionar las diferentes opciones posibles con las que se podría abordar su reintegración, así como los resultados finales del bien cultural una vez aplicadas las mismas. Nos referimos concretamente a una imagen virtual que reflejase el aspecto que podría adoptar ese bien tras el tratamiento informatizado de sus lagunas y desgastes, a partir de imágenes digitalizadas de la obra (general y/o detalles) tratadas informáticamente; de esta forma, en la decisión final que se adopte, además de valorar las consideraciones técnicas, conservativas y operativas usuales, se evaluará también el aspecto que podría adquirir la imagen final de la obra digitalizada y tratada virtualmente con cada uno de los sistemas de reintegración que se hayan seleccionado.

En los últimos años, el desarrollo de los sistemas multimedia ha abierto el campo de la investigación aplicada a la intervención de bienes culturales no sólo a los campos tradicionales, que en el caso que nos ocupa, la reintegración de lagunas, se centran más en las técnicas, materiales y sistemas, sino también a las posibilidades que nos brinda el tratamiento digital de la imagen. Las investigaciones que en este sentido se vienen efectuando en nuestro país se orientan hacia su aplicación a la intervención en bienes culturales, concretándose en tratamientos complejos como los estudios de correspondencia de capas policromas, la limpieza virtual de imágenes, la impresión digitalizada y también en la reintegración informatizada (ARQUILLO AVILÉS, 2000; RUIZ DE ARCAUTE MARTÍNEZ, 2002; ESCRIG MORENO y PUERTES TORRENT, 1994).

En nuestro caso la investigación se ha centrado únicamente en poner a punto un sistema de reintegración virtual de lagunas que permita evaluar la incidencia de los distintos sistemas de reintegración en el aspecto final de un bien cultural dado; para ello se ha empleado el software actualmente disponible en el mercado, de modo que, una vez puesto a punto el método, pueda ser fácilmente desarrollado por cualquier especialista en la materia.

Esta investigación se enmarca dentro del proyecto que promueve el Instituto Andaluz del Patrimonio Histórico (IAPH) y el Departamento de Pintura de la Universidad de Sevilla para el proyecto de intervención en las pinturas de La Sala de los Reyes de la Alhambra de Granada'.

Los estudios efectuados y actuaciones desarrolladas en las pinturas de La Sala de los Reyes contempladas en los respectivos proyectos de intervención formulados por el IAPH y el Patronato de la Alhambra y Generalife (PAG) han generado una documentación suficiente para conocer su evolución temporal e interrelacionar su actual estado de conservación con los agentes de alteración y con las intervenciones restaurativas que, de forma sistemática, se han venido realizando en su conjunto. Esta documentación, de excelente calidad, ha servido de base y ha permitido diseñar y poner a punto el método para su reintegración virtual. 


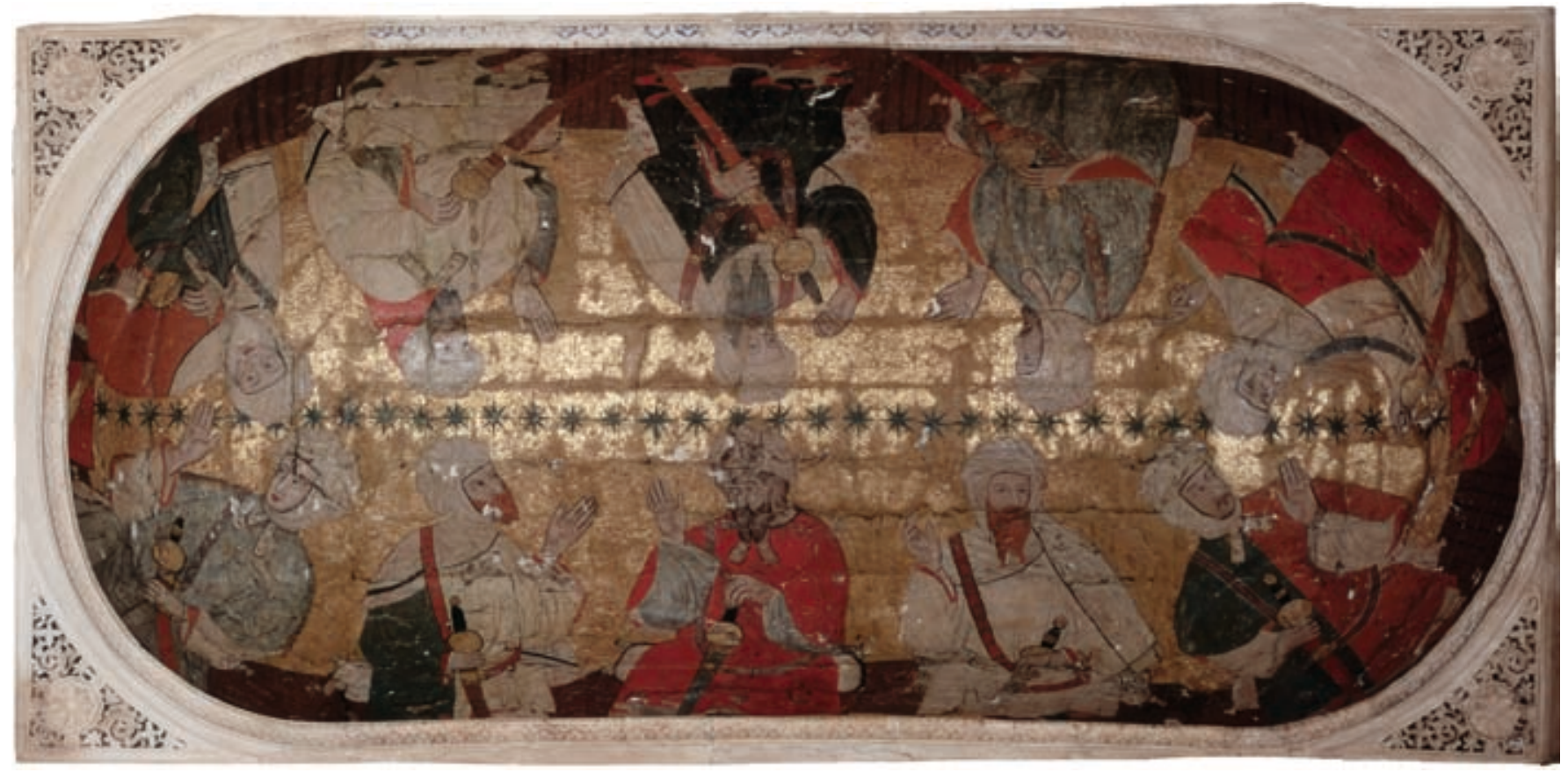

Ortofotogrametria de la sala $\mathrm{n}^{\circ} 2$ de la sala de los Reyes de la Alhambra de Granada. Fuente: Map Line SA. Patronato de la Alhambra y Generalife

El estado de conservación de las pinturas de La Sala de los Reyes es fruto de la acción de diversos agentes que han interferido en su conjunto, afectando muy negativamente a su evolución material con la aparición y desarrollo de múltiples patologías en todos sus estratos constitutivos (soporte -madera y cuero-, conjunto pictórico y dorado -original, repintes y reintegraciones-) derivadas de las intervenciones que con carácter reparador o de restauración se han realizado sobre todo en los primeros tres cuartos del s. XX. El estado de su superficie pictórica resulta muy irregular en cuanto a levantamientos, deformaciones del soporte, lagunas a distintos niveles -cuero, preparación, color- y desgastes, además de numerosos repintes y reintegraciones ejecutados con distintos criterios y resultados que implican consideraciones a priori a la hora de definir la intervención que requiere el anverso en su conjunto. Todos estos considerandos hacen de estas pinturas un caso idóneo para desarrollar un método de trabajo que permita, por un lado, establecer la metodología y las pautas para su ejecución, y por otro, servir de documentación base para su aplicación en el conjunto de las pinturas con vistas a la toma de decisión que se adopte en fase de restauración.

\section{METODOLOGÍA}

El estudio de la documentación existente sobre estas pinturas es muy amplio en el tiempo, variado por los soportes y formatos en que se encuentra, y numeroso en cuanto a la cantidad de documentos generados por los distintos especialistas e instituciones que las han venido estudiando o custodiando. Por ello, se ha debido evaluar la documentación de partida para seleccionar los motivos y las imágenes que servirán de base para este trabajo, contrastándose durante el proceso la documentación que sobre ese motivo en concreto está disponible (calcos en papel vegetal de las pinturas, gráfico realizados por Owen Jones, fotografías del archivo PAG realizadas por Oronoz y la documentación gráfica y fotográfica generada por el proyecto -infografías, gráficos, ortofotogrametría, fotogrametría y fotografías- IAPH-PAG).

La metodologia general seguida se expone a continuación:

\section{Selección de la imagen}

En la selección de la imagen se ha primado criterios de representatividad en el conjunto de las tres pinturas:

- Detalle figurativo, personaje o motivo animal representativo del conjunto de la pintura.

- Estado de conservación lacunar, además de áreas de desgastes y repintes.

- Documentación disponible del motivo representativo de su evolución temporal, conservativa y estética.

Este trabajo se ha articulado en dos fases:

1. Realización de pruebas y ensayos para evaluar métodos y aplicaciones de las distintas versiones del software a utilizar en base a nuestras exigencias. En las primeras pruebas se decidió emplear el rostro que ambas instituciones han utilizado para identificar el Proyecto de intervención de estas pinturas: fragmento de la cara del rey 4 de la pintura $n^{\circ} 2$ de la Sala de los Reyes.

2. Evaluación de los primeros resultados y desarrollo del método, aplicaciones y herramientas para que, una vez determinado el proceso, se pudiese aplicar al motivo final elegido. Para esta fase se seleccionó un área de trabajo de mayor dimensión cuyo estado de conservación fuese representativo del conjunto de las pinturas, siendo el motivo seleccionado el caballo situado en la bóveda 1 , 
en el cascarón con latitud norte de la zona del Partal en dirección a la Bóveda 2.

\section{Software empleado}

Entre los diferentes modelos de software existentes en el mercado, que se ajustan a las necesidades de este proyecto, desde un primer momento se plantea la necesidad de contrastar la conveniencia de usar Adobe Photoshop o CorelDraw. El análisis comparativo de ambos software nos lleva a tomar la decisión de emplear el segundo de ellos, CorelDraw, porque ofrece mejores prestaciones procedimentales que el primero. Por un lado, brinda la posibilidad de trabajar con imágenes vectoriales que resultan más flexibles que los mapas de bits, con los que trabaja Adobe Photoshop, porque las imágenes pueden ser redimensionadas y extendidas sin perder calidad de información, y su representación suele requerir menos memoria y espacio de almacenamiento. Por otro lado, para el tratamiento de la imagen según los fines que persigue este proyecto, CorelDraw presenta un manejo más sencillo y eficaz porque simplifica la aplicación de las diferentes funciones que recoge tanto en su Caja de herramientas como en su Cuadro de diálogo.

CorelDraw es un programa de dibujo vectorial que facilita la creación de ilustraciones profesionales: desde simples logotipos a complejas ilustraciones técnicas. Proporciona una amplia variedad de herramientas y efectos que permiten trabajar de manera eficiente para producir gráficos de alta calidad, enviar una ilustración a un servicio de filmación para su impresión o para la publicación de un documento en internet. Entre sus herramientas debemos destacar, por su alto grado de eficiencia para los fines del proyecto, la herramienta Bézier y Elipse, que facilitan la aplicación de los diferentes sistemas de reintegración, así como la herramienta Relleno que permite determinar, en base a su aplicación, la tonalidad cromática idónea para cada caso y sistema de reintegración, tanto en lo tocante a los contornos como a los rellenos de las lagunas.

En un principio se comienza a trabajar con la versión 8 de CorelDraw, por las facilidades de manejo que presenta, hasta que se decide optar por la versión 12 porque ofrece las mismas facilidades procedimentales pero una mayor versatilidad, ya que aportaba una ampliación de las funciones recogidas en la Caja de herramientas, con dos nuevas destinadas a las herramientas de Dibujo inteligente y de Papel gráfico, y una ligera mejora en todos los aspectos generales. De este modo, CorelDraw 12 se configura como uno de los programas de diseño y dibujo vectorial más completos que existen en la actualidad, marcando una auténtica evolución en el concepto del diseño gráfico porque es el primero en ofrecer herramientas inteligentes que simplifican el proceso de diseño, reducen el tiempo de revisión y reutilización de gráficos, y proporcionan más control sobre textos y objetos, lo que ayuda en gran medida a diseñar con mayor precisión. Por todo ello CorelDraw 12 se muestra como un software de gran calidad y efectividad para la edición digital de imágenes.
Análisis virtual de la pintura: determinación del original y su evolución

Una vez determinados los motivos, se procedió a seleccionar y clasificar las imágenes que de ellos disponíamos para su digitalización y/o tratamiento informático, según el formato de origen del documento original; siendo documentación base para esta parte del trabajo el calco en vegetal del rey seleccionado que data de 1908 y las fotos realizadas por Oronoz en la década de los 70 del siglo pasado. Tras lo cual se procedió a individuar de la imagen base las lagunas, desgastes y repintes documentados en el tiempo. En esta primera fase del trabajo se decidió iniciar el proceso a partir de las lagunas presentes en esta área de la pintura antes de que fuese protegida con la aplicación de un empapelado de protección, correspondiente a la fase de intervención de emergencia ejecutado en $2006^{2}$.

\section{Selección de los sistemas de reintegración}

Con objeto de disponer de un máximo de resultados posibles de un mismo motivo, que pueda ayudar a la toma de decisión final que se adopte en estas pinturas, se han valorado los sistemas de reintegración que creemos más compatibles con las características de la pintura y con su ubicación, ya que por la distancia a la que el espectador las puede percibir, los sistemas discernibles se integrarian tanto como el invisible o mimético, dando la sensación de continuidad en ambos casos. Por lo que en este trabajo se han utilizados los siguientes: rigatino, puntillismo y tinta plana o neutra.

A continuación se desarrolla el método seguido en su ejecución distinguiendo entre las partes comunes y las individuales de cada sistema.

\section{TRATAMIENTO VIRTUAL DE LAGUNAS CON LOS SISTEMAS DE REINTEGRACIÓN SELECCIONADOS. PROCESO}

Una vez seleccionado el motivo y los sistemas de reintegración a emplear, se determinó el orden a seguir: primero rigatino, después tintas planas y, por último, puntillismo. El proceso seguido fue el siguiente:

\section{Importación de la imagen al programa CoreIDRAW 12}

Se abre un archivo de trabajo nuevo y se guarda y denomina para no perderlo, a continuación se selecciona el archivo que queremos importar, para ello, en la herramienta Archivo, se marca Importar; seguidamente, se selecciona la foto del archivo en la que se quiere trabajar y se confirma presionando Intro. Aparece en el documento de trabajo una escuadra con el nombre de la foto seleccionada y se confirma pulsando Intro. Una vez que se muestra la imagen en el documento que tenemos abierto, se ajusta en tamaño y posición al formato de pantalla o de impresión, como mejor nos convenga. 

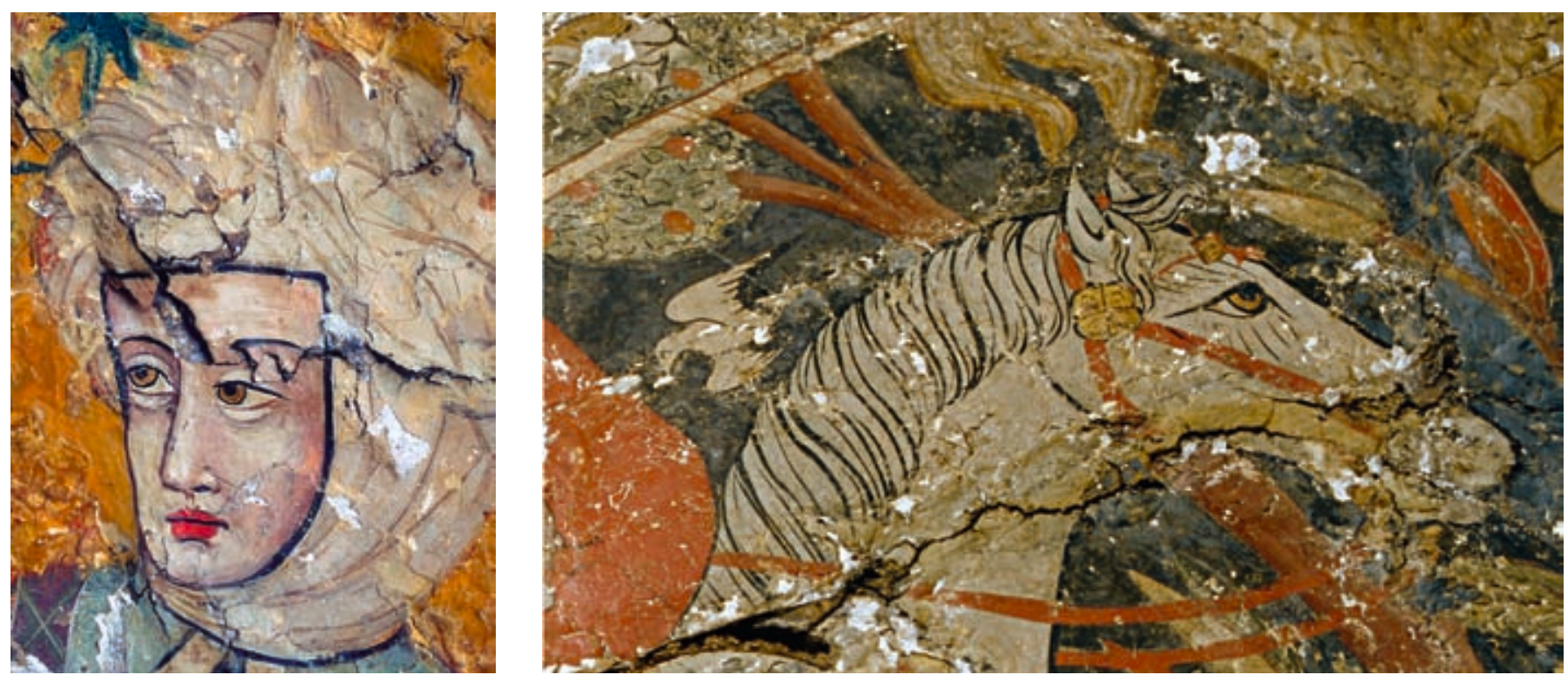

Motivos seleccionados. Detalle de la cabeza del rey 4 de la sala nº 2 y detalle del caballo de la sala no 4 . Fotos: José Manuel Santos Madrid, IAPH (izquierda) y Vicente del Amo, Patronato de la Alhambra y Generalife (derecha)

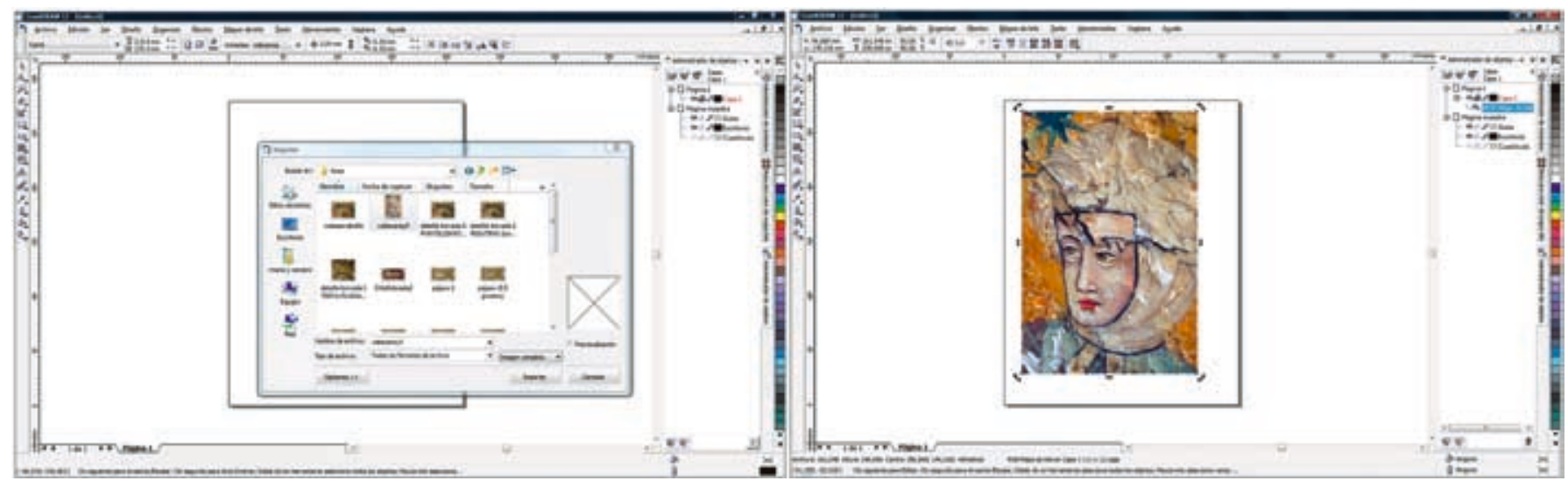

Importación de la imagen al archivo de trabajo

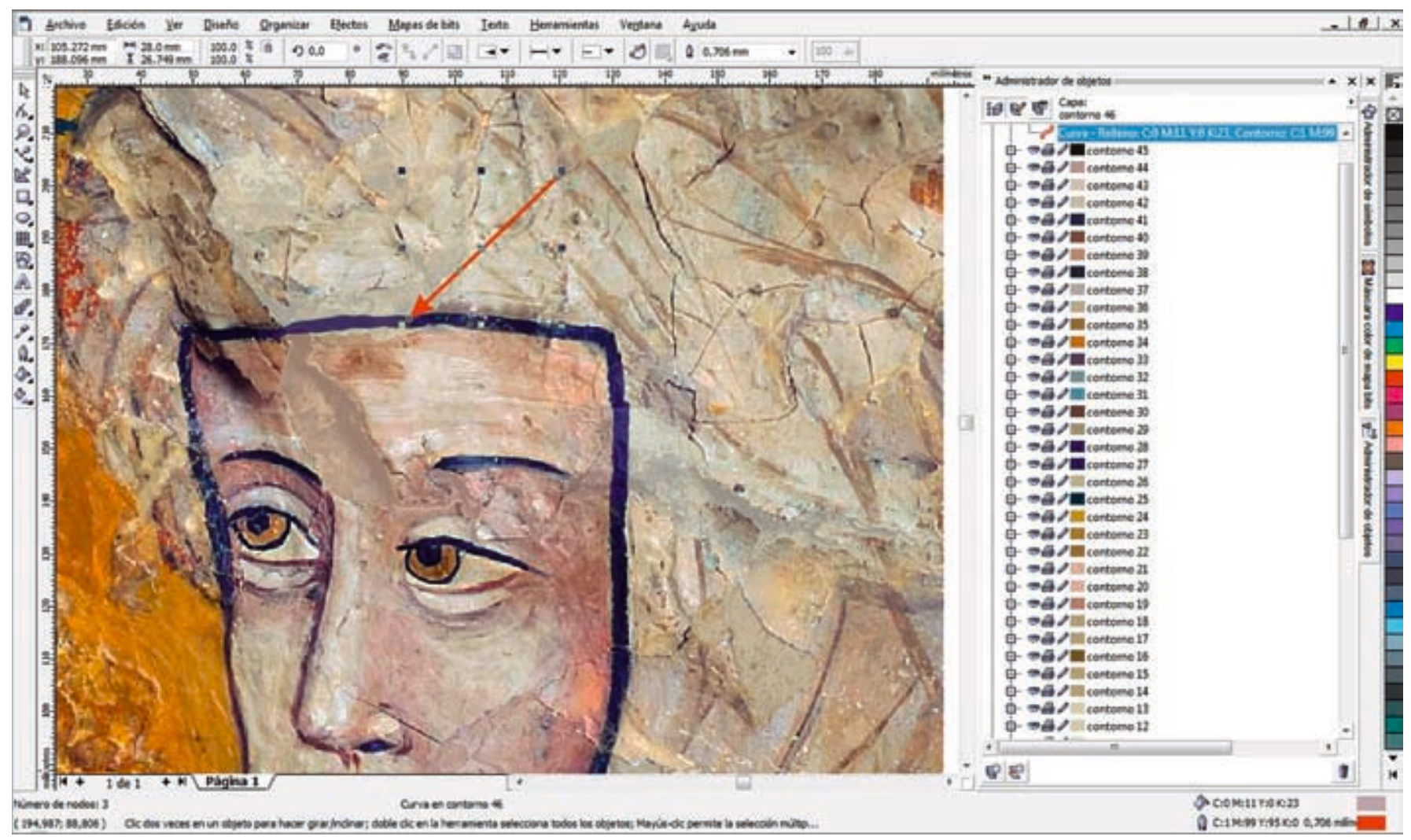

Detalle de la delimitación del contorno de la laguna 

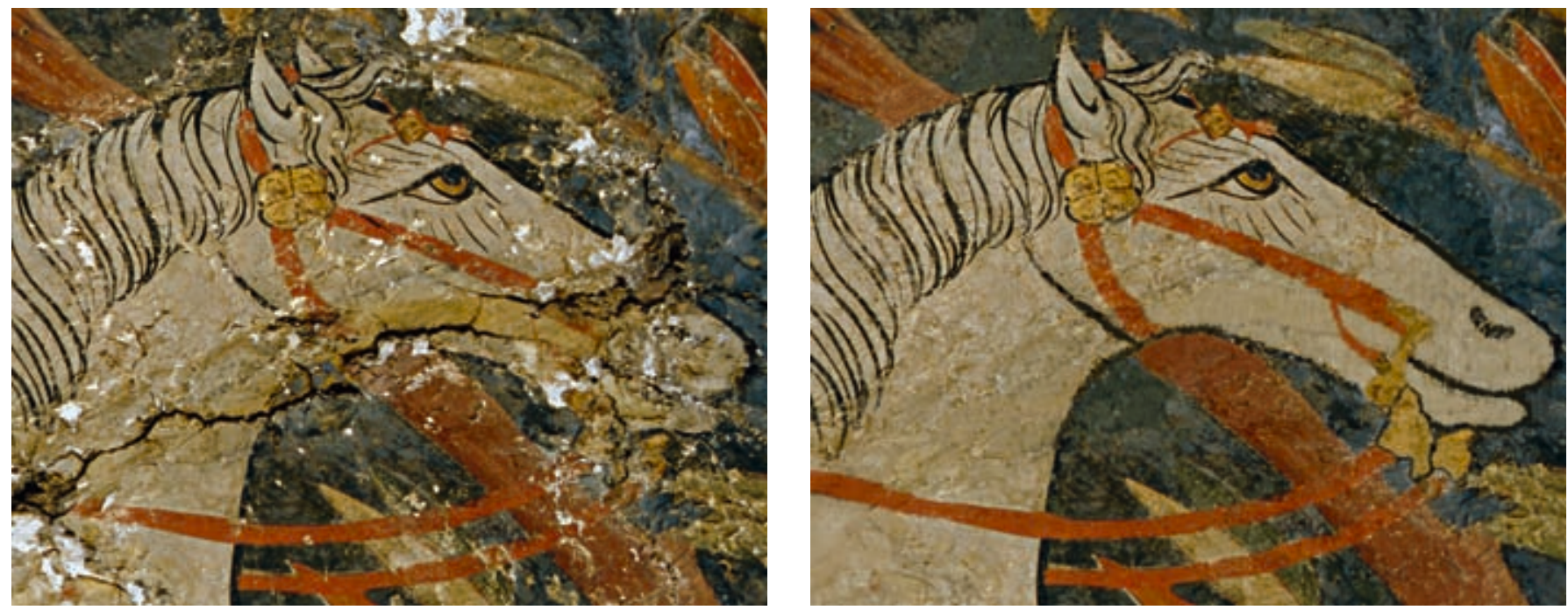

Detalle de la reintegración virtual de la cabeza del caballo. Sistema de reintegración rigatino
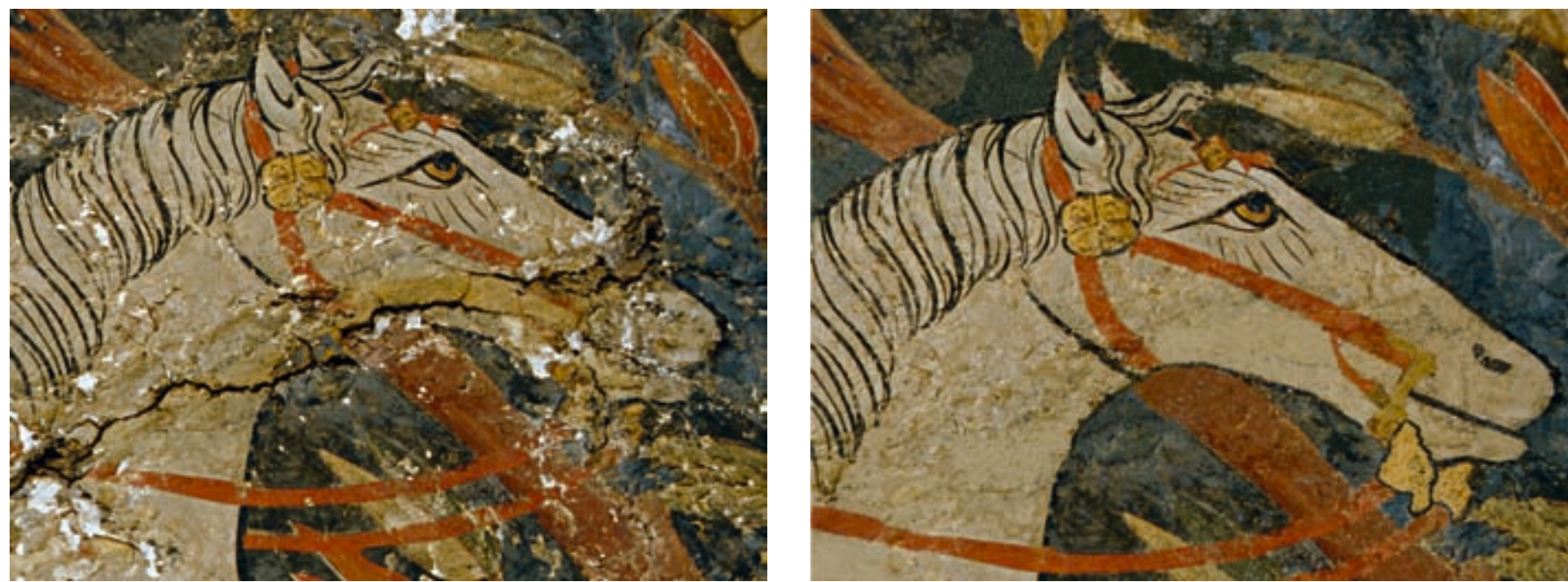

Detalle de la reintegración virtual de la cabeza del caballo. Sistema de reintegración puntillismo
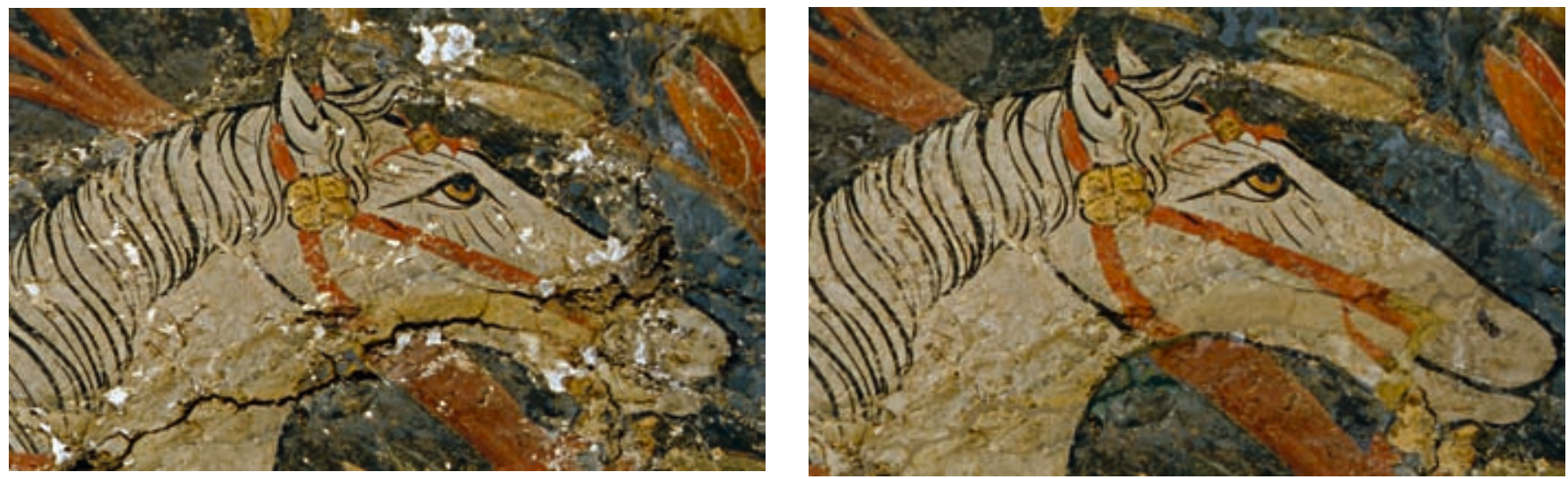

Detalle de la reintegración virtual de la cabeza del caballo. Sistema de reintegración tinta plana

Se han valorado los sistemas de reintegración que creemos más compatibles con las características de la pintura y su ubicación, teniendo en cuenta la distancia a la que el espectador las puede percibir 


\section{Gestión y denominación de capas}

La gestión por capas es la forma que hemos considerado más eficaz para desarrollar y organizar nuestro trabajo, para activarla y poder definir y trabajar con ellas, en Herramientas, en el cuadro de diálogo que se despliega se selecciona Administrador de capas y se abren y denominan cuantas capas vayamos necesitando a medida que trabajamos.

El cuadro de diálogo de configuración correspondiente a cada capa proporciona controles que ayudan a organizar la información en ellas contenida. Estos controles permiten ver, imprimir o editar una capa, ubicar el contenido de una capa en cada página de un documento, e incluso, cambiar el nombre, reorganizar las capas o suprimir la visualización a todo color de una capa, de forma que el contenido aparezca como contornos de un color determinado.

La primera capa es la foto original que hemos importado, que se bloquea para que no se pueda tocar y no se realicen reintegraciones virtuales. El objetivo es que la foto original quede como base, generándose una copia, para poder manipularla si fuera necesario.

Se abren y denominan tantas capas como lagunas se vayan a tratar virtualmente. Es recomendable, a medida que se va trabajando e incorporando información en las capas, activar o desactivar la casilla Editable de cada una de ellas, representada en forma de lápiz, con objeto de no mezclar o perder información.

Cada una de las capas que hemos realizado por cada laguna, podemos abrirlas pinchando en el signo + que se encuentra en el cuadro de diálogo, y nos saldrá toda la información que hemos colocado en esa laguna; por ejemplo, en el caso del puntillismo, cuántas elipses hemos colocado y su color en el modelo de color RGB con el que hemos trabajado.

Dentro de los diversos modelos de colores con los que se puede trabajar de modo infográfico con el software CorelDraw 12 para representar todo el espectro cromático (RGB, CYM, CMYK, HSB, HLS, Lab, YIO) hemos optado por el modelo de color RGB (Red, Green, Blue) que representa los colores primarios luz (rojo, verde y azul) frente a los colores primarios pigmento (magenta, cian y amarillo), porque resulta más adecuado para representar imágenes que serán mostradas en monitores de $\mathrm{PC}$, como es nuestro caso, o impresas en papel fotográfico.

\section{Delimitación del contorno de la laguna y relleno de un tono base}

El proceso se ha iniciado de forma similar a cuando se efectúa una reintegración sobre una obra real, es decir, mediante la aplicación de un tono base que ayude a integrar la laguna con el contexto y con el contorno, lo que normalmente se denomina "cubrir blancos".
Se delimitan los contornos de las lagunas y se rellena con un color base claro, nunca opaco, con la finalidad de dotarla de una transparencia uniforme que deje ver el fondo de la fotografía. Lo que se pretende con esto es aplicar un color semejante en cuanto al matiz y al tono con objeto de facilitar la integración de la laguna en el contexto y conseguir que se mimeticen sus bordes para mejorar el efecto de unicidad de la laguna con el resto de la imagen. Sobre este tono base, se ejecutará el sistema de reintegración.

\section{Ejecución del sistema de reintegración}

Con independencia del sistema de reintegración seleccionado, se describen a continuación los pasos comunes a todos ellos.

\section{Sistema de reintegración}

- Rigatino. Para realizar las líneas del rigatino se utiliza la herramienta Bézier, a la que se llega seleccionando en la caja de herramientas, situada en el borde izquierdo de la pantalla, el cuarto botón comenzando por arriba, la herramienta Mano alzada. Entonces se pincha con el botón izquierdo del ratón sobre el ángulo inferior derecho de esta herramienta y se despliega un menú donde aparece la herramienta Bézier, segundo botón comenzando por la izquierda del menú. Una vez seleccionada, esta herramienta pasa automáticamente a formar parte del menú de la caja de herramientas, sustituyendo a la herramienta Mano alzada y, por lo tanto, apareciendo como el cuarto botón superior de este menú. Después de dibujar la línea con la herramienta Bézier, se selecciona el color que se va a poner en la laguna con la herramienta contorno, tercer botón inferior del menú de la caja de herramientas. Cuando ya hemos obtenido del contorno de la laguna el color adecuado para rellenarla, se selecciona la línea y se le adjudica el color obtenido, a continuación se copia y se pega varias veces hasta formar un bloque de líneas, y ya sólo queda copiar y pegar este bloque tantas veces como sea necesario para cubrir completamente la laguna. Asi se hace, una y otra vez, con la gama de colores necesaria, superponiendo unos bloques a otros hasta completar la laguna. Hay que precisar que cada color, cuando se aplica, forma su propia capa de modo que, si en algún momento deseamos que una capa no quede a la vista, o bien que sea suprimida, podemos hacerlo como hemos especificado antes (véase apartado 2, Gestión y denominación de capas, de la sección Tratamiento virtual de lagunas con los sistemas de reintegración seleccionados).

- Puntillismo. En el caso del puntillismo el procedimiento empleado es el mismo, salvo que se parte de una elipse, en lugar de una línea, para obtener la forma del punto empleado en esta técnica. Para ello, se selecciona en la caja de herramientas, la herramienta Elipse, séptimo botón superior del menú, y se sigue el mismo procedimiento, paso por paso, descrito para el rigatino.

- Tinta plana. Para la reintegración con este método debemos realizar en primer lugar una delimitación del contorno de la laguna con la herramienta Bézier, después rellenarla con un tono similar 


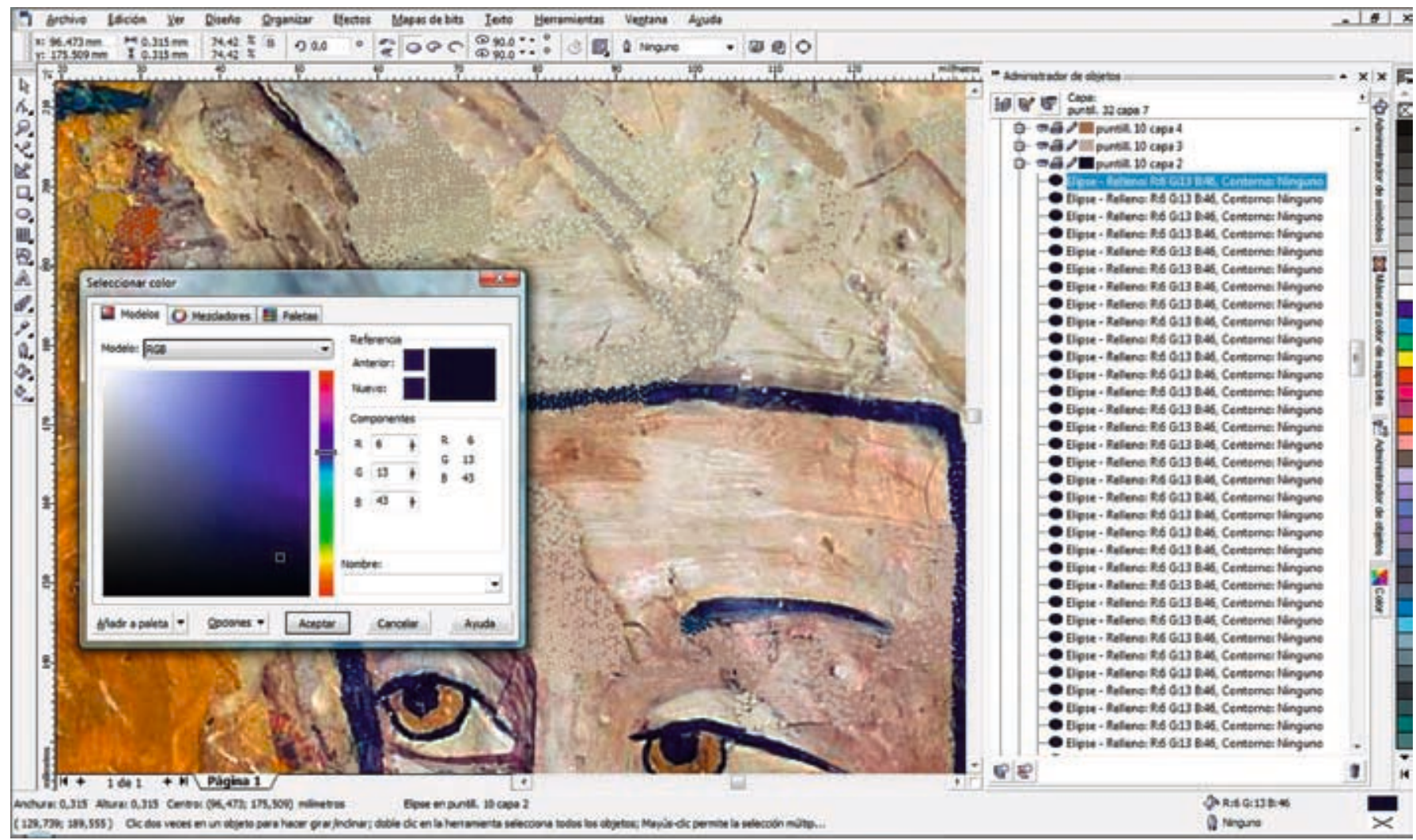

Detalle del sistema de trabajo con el modelo de color RGB

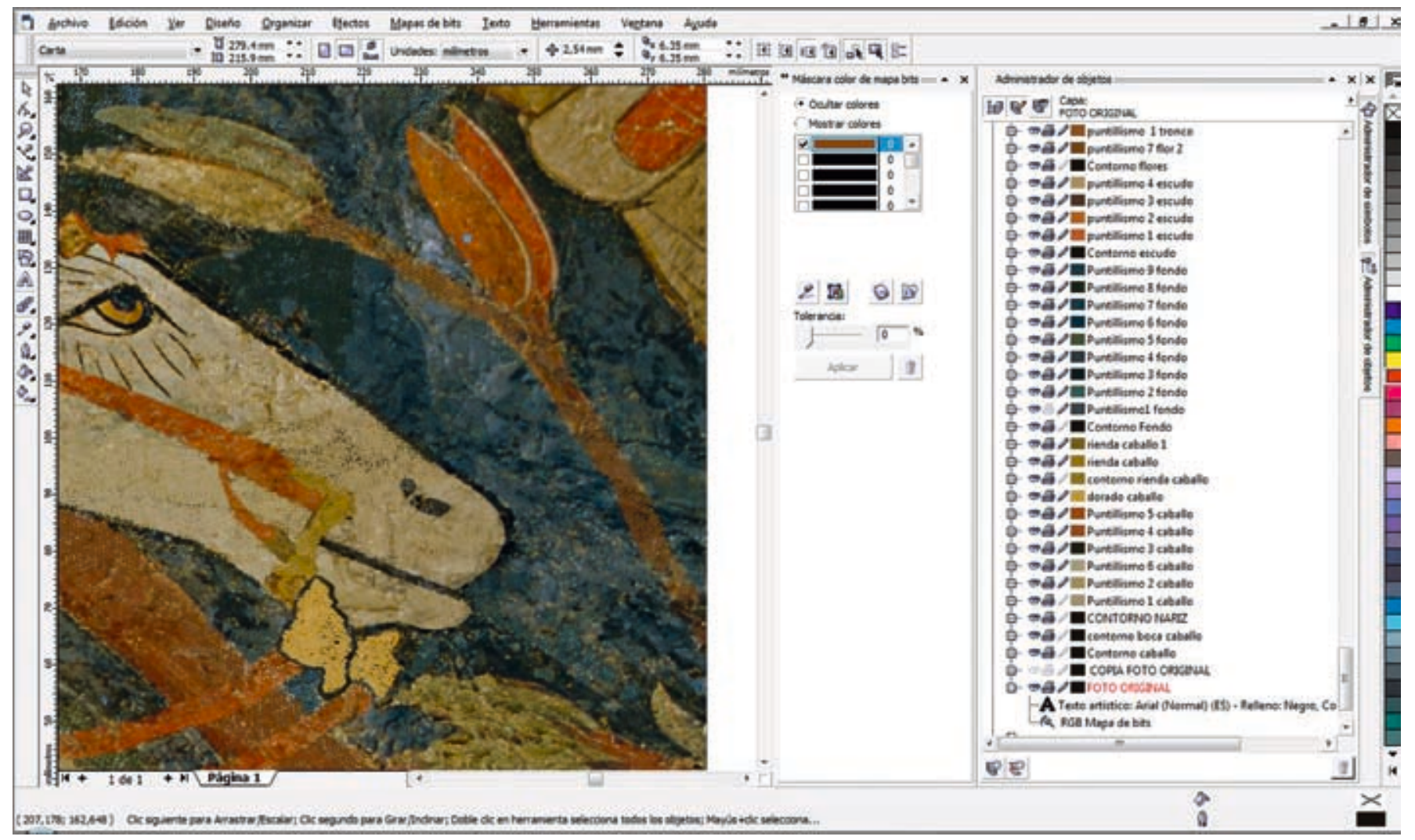

Selección de color mediante la herramienta selector color y editar color

Entre los dos métodos usados para seleccionar el color, nos hemos decantado por el segundo porque presenta una ventaja fundamental y determinante sobre el primero: los colores que se seleccionan tienen

el mismo RGB que el original digitalizado 
al de la pérdida, en un bajo tono transparente, para, de este modo, diferenciarlo del original sin que se produzca a la vez un gran contraste entre ambas partes. Por otra parte debemos destacar que, al igual que en los sistemas de reintegraciones anteriores, cada laguna tiene su propia y única capa de color, diferenciándose unas de otras por el color representado en el cuadro de diálogo que aparece a nuestra derecha.

\section{Selección de colores}

Se han utilizado dos procedimientos diferentes para seleccionar el color. El primero de ellos consiste en la selección visual del tono que se desea reproducir a partir del cuadro de diálogo Administración de color, al que se llega pinchando sobre el botón de la herramienta Relleno y seleccionando, en el menú que a continuación se abre a la derecha de esta herramienta, el séptimo o último botón. Entonces aparece, a la derecha de la pantalla, el cuadro de diálogo Administración de color. Este cuadro ofrece una paleta de colores de entre los que se debe escoger el color y tono más afín al color original que tendria la laguna. Por lo tanto, puesto que desconocemos el RBG de la obra original, la determinación del color resulta subjetiva, realizada siguiendo criterios cromáticos por aproximación al color original. Este procedimiento ha sido utilizado para la identificación de las lagunas en el gráfico de la bóveda 2.

En el segundo procedimiento, se utiliza la herramienta Mapa de bits, situada en la barra de menú, parte superior de la pantalla. Cuando se pincha sobre esta herramienta se abre un cuadro de diálogo en la parte derecha de la pantalla denominado Máscara de color de mapa bits. A partir de aquí, se selecciona primero la foto original, asegurándonos de que ésta no se encuentre bloqueada por la opción Editable, representada por un lápiz, y a continuación nos posicionamos sobre el color a reproducir de la foto original, marcando con anterioridad la opción Selector de color, representada por un cuentagotas. Si se pincha sobre dicho color se obtiene información precisa (RBG) al respecto del tono original con el que se pretende reintegrar la laguna. Esta información objetiva permite elegir los tonos más adecuados para realizar la reintegración sin perder nunca la referencia de las caracteristicas cromáticas de la obra original digitalizada, logrando así unos tonos más reales porque se aplican en la reintegración los mismos tonos que los de la obra original obtenida a partir de la imagen digitalizada.

Una vez seleccionadas las variantes de color que van a ser utilizadas para la reintegración, se marca cada una de ellas y se pincha sobre el cuadro Editar color, situado en el cuadro de diálogo Máscara de color de mapa bits, en forma de un cuadrado de colores en el interior de un cuadrado en blanco y negro, para obtener el RGB de las variantes seleccionadas y determinar cuáles son las más favorables para nuestras reintegraciones cromáticas virtuales. Una vez definidas las variantes más afines, se anota su RGB, y para obtener esa misma variante, pinchamos sobre la pestaña Administrador de objetos. Entonces nos sale un cuadro de diálo-
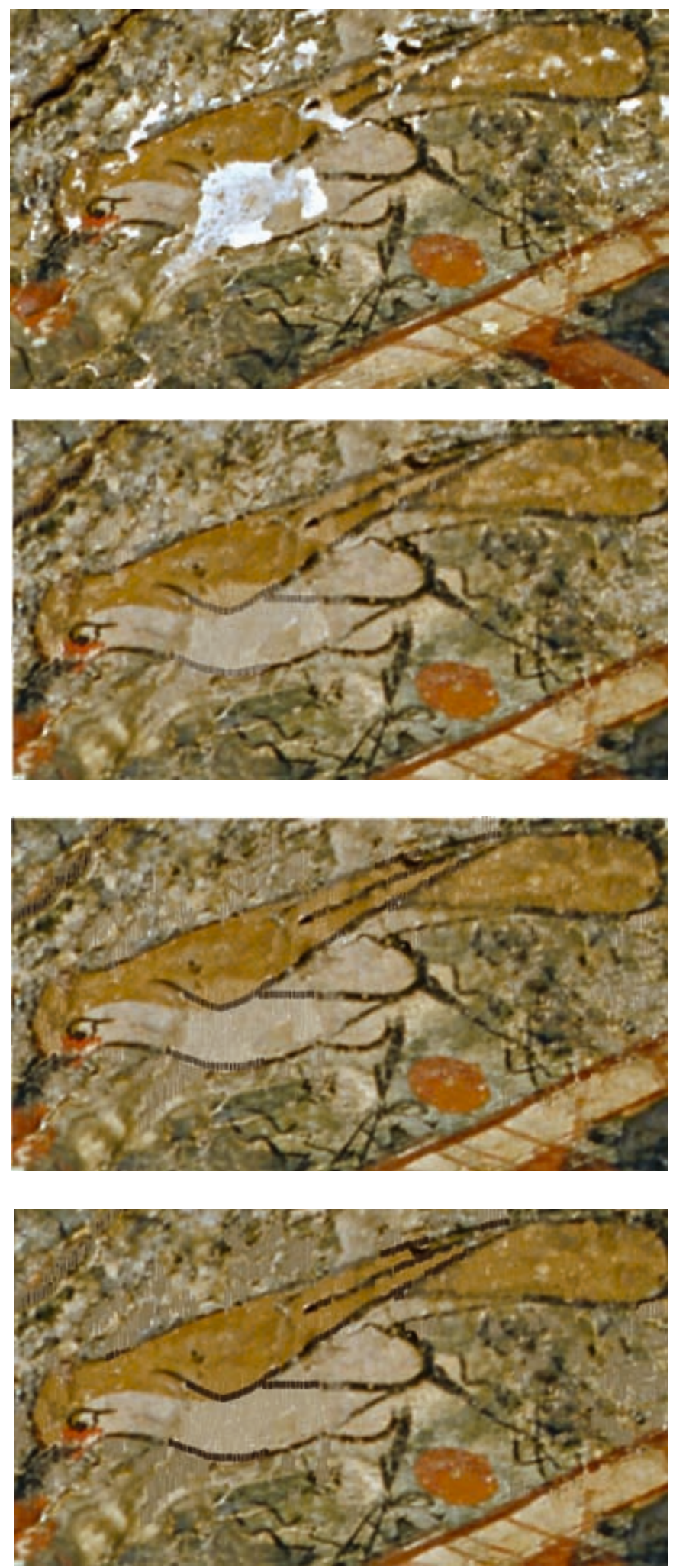

Estudio del grosor de la línea base del sistema de reintegración rigatino

go donde podemos marcar las diferentes capas de reintegración correspondientes a cada capa de color con el que vayamos a trabajar, se pincha dos veces sobre el recuadro negro que aparece junto a cada capa y se selecciona el botón Otros. A continuación, aparece, en el centro de la pantalla, un cuadro denominado Seleccionar color, pinchamos en la pestaña Modelo, se despliega el menú y seleccionamos RGB. Ahora toca insertar en Componentes el RGB que hemos anotado previamente y dar al botón Aceptar. Ya hemos definido, siguiendo el RGB del color original, la variante cromática que se va a aplicar en esa capa, sólo queda rellenar o 

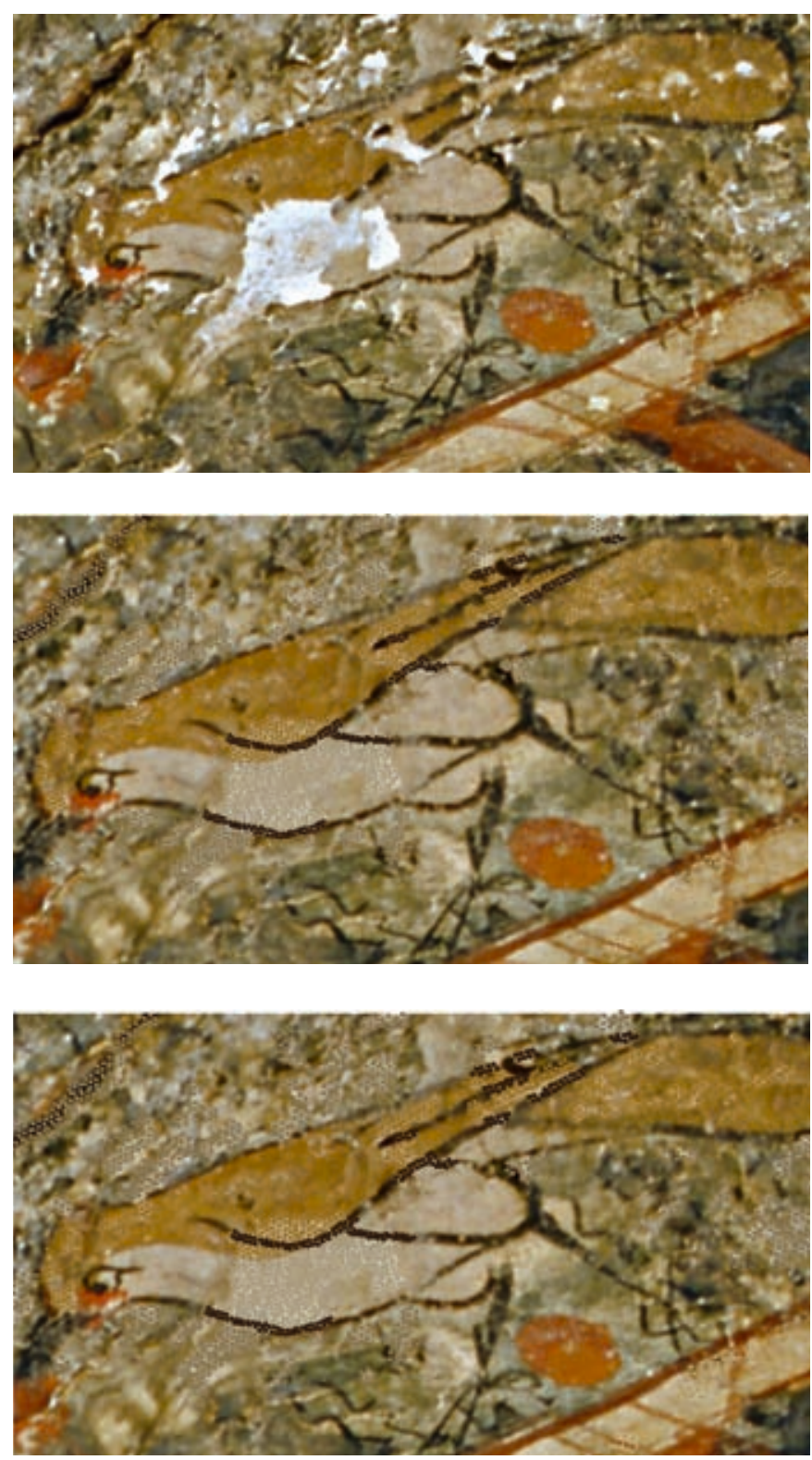

Estudio del grosor de la elipse base del sistema de reintegración puntillismo

contornear con este color nuestra reintegración, según se trate de una línea, una elipse o un área de relleno.

Ambos sistemas de selección del color comparten una característica que facilita la operación de rellenado de color: una vez que se determina y se aplica el tono que se precisa para el relleno de un grupo de elipses o un grupo de líneas para crear la reintegración cromática de una laguna (véase párrafo anterior), se pueden copiar los rellenos de un objeto a otro sin tener que volver a crear rellenos complejos, es decir, una vez que se ha creado el relleno que se considera más apropiado, bien de forma objetiva o subjetiva, se puede indicar que sea el relleno predeterminado y así poder utilizarlo en todas las lagunas. Para ello, tan sólo hay que seleccionar el bloque de reintegración de líneas o elipses ya rellenas, copiarlo y pegarlo reiteradamente hasta cubrir la laguna.

Entre los dos métodos usados para seleccionar el color, nos hemos decantado por el segundo porque presenta una ventaja fundamental y determinante sobre el primero: Ios colores que se seleccionan tienen el mismo RGB que el original digitalizado, lo que permite una visualización del color más correcta que con el primer método donde la selección de los colores se realiza por semejanza y siguiendo el criterio subjetivo del conservadorrestaurador.

\section{Reintegración por bloques}

Una vez determinados de forma objetiva, siguiendo el procedimiento anteriormente expuesto, los colores que se van a aplicar en los diferentes tipos de reintegraciones, colores que irán separados por capas, se aplican a las líneas del rigatino o a las elipses del punteado, previamente seleccionadas, y, a continuación, se copian y pegan las veces necesarias para crear el bloque deseado. Finalmente, una vez conformado el bloque de reintegración, se selecciona todo el conjunto, se copia y se pega reiteradamente hasta rellenar la laguna, que, con anterioridad, ha tenido que ser coloreada con un tono base neutro para "cubrir los blancos". Esto se consigue con la herramienta Bézier: se selecciona esta herramienta, se marca sobre el contorno de la laguna hasta dibujarlo, se le asigna el color previamente obtenido siguiendo el procedimiento anteriormente reseñado, y se le proporciona una transparencia. La herramienta de transparencia se encuentra en la caja de herramienta, situada en el botón quinto inferior denominada Herramienta Mezcla interactiva, se pincha en el ángulo inferior con el botón izquierdo, apareciendo un menú a la derecha donde se seleccionará la Herramienta Mezcla interactiva. En la barra de propiedades situada en la zona superior de la pantalla se pincha la casilla donde aparece Ninguno accionando la opción Uniforme. Por último, cambiaremos la Transparencia inicial dejando ver la foto original con el tono base transparente que deseamos.

Estudio del grosor y la anchura de los elementos de reintegración (líneas y puntos)

Para determinar las características morfológicas de las herramientas que ibamos a utilizar y su adecuación a los sistemas de reintegración de rigatino y punteado de forma virtual, se ha llevado a cabo un estudio previo sobre la imagen de la bóveda no 1 en la que se han ensayado diferentes grosores de líneas y contornos, probándose para ello diversas medidas posibles que permitiesen determinar la anchura, grosor o tamaño de los diversos elementos de dibujo con vistas a obtener información relevante que permitiese su posterior aplicación en las diferentes lagunas en función de sus necesidades y morfología. Las medidas probadas van desde los 0,5 puntos hasta llegar a los 3 puntos, con un intervalo progresivo de 0,5 en 0,5 puntos.

Cabe decir que para seleccionar la anchura de las líneas de reintegración se marca, en el menú de herramienta, la herramienta Contorno y dentro de ésta la herramienta Cuadro de diálogo, Pluma de contorno donde las anchuras de las líneas pueden ser modificadas por el usuario, según las necesidades de reintegración de la laguna o los criterios establecidos a tal efecto. 
Al igual que en el caso de las diferentes anchuras de las líneas de reintegración, también se ha realizado un estudio en referencia al grosor del punto para los procedimientos de reintegración que se han llevado a cabo siguiendo el sistema del puntillismo. Para ello, se han realizado pruebas con puntos de diversos grosores, con el mismo fin que en el estudio anterior, es decir, determinar el grosor que mejor se ajusta a las necesidades de cada laguna. El procedimiento para modificar el grosor de los puntos se limita a marcar la elipse en el menú de herramientas y darle el tamaño requerido con el ratón, extendiendo o reduciendo la elipse sin dejar de marcarla hasta conseguir las medidas deseadas, aunque siempre puede ser modificada posteriormente.

\section{Estudios complementarios por realizar}

El mayor problema que plantea el sistema empleado es que se parte de la imagen digitalizada de la obra, y no de mediciones de color de la obra real. La imagen digital de la obra de partida llega transformada al ordenador a través de la fotografía y la digitalización, influenciada también por las condiciones de iluminación con las que la imagen fue obtenida o, si se parte de una imagen escaneada, de la variación derivada de la impresión.

Somos conscientes de que el proceso que hemos descrito debe ser contrastado con un método de medición real de los colores con el Colorimetro Tristimolo CR31 tomados a partir de la obra y no de su imagen digitalizada que nos permita obtener mediaciones colorimétricas de cada color, que una vez traspasada la imagen al ordenador, puede llevarse a cabo su tratamiento, manipulación y procesado sin aberraciones cromáticas. Por ello se pretende completar este estudio en fase de actuación en el anverso de las pinturas, una vez que se puedan efectuar mediciones colorimétricas sobre la obras desprovista del facing de protección que las protege en la actualidad. El proceso que se pretende llevar a cabo se describe someramente a continuación

- Estudio colorimétrico de la superficie tras la remoción del facing. Colorímetro Tristimolo CR31.

- Aplicación de las coordenadas cromáticas de los colores derivadas del estudio colorimétrico al tratamiento virtual de lagunas.

- Reconstrucción virtual con datos reales derivados del estudio colorimétrico efectuado.

\section{Somos conscientes de que el proceso} que hemos descrito debe ser contrastado con un método de medición real de los colores con el Colorimetro Tristimolo CR31 tomados a partir de la obra y no de su imagen digitalizada

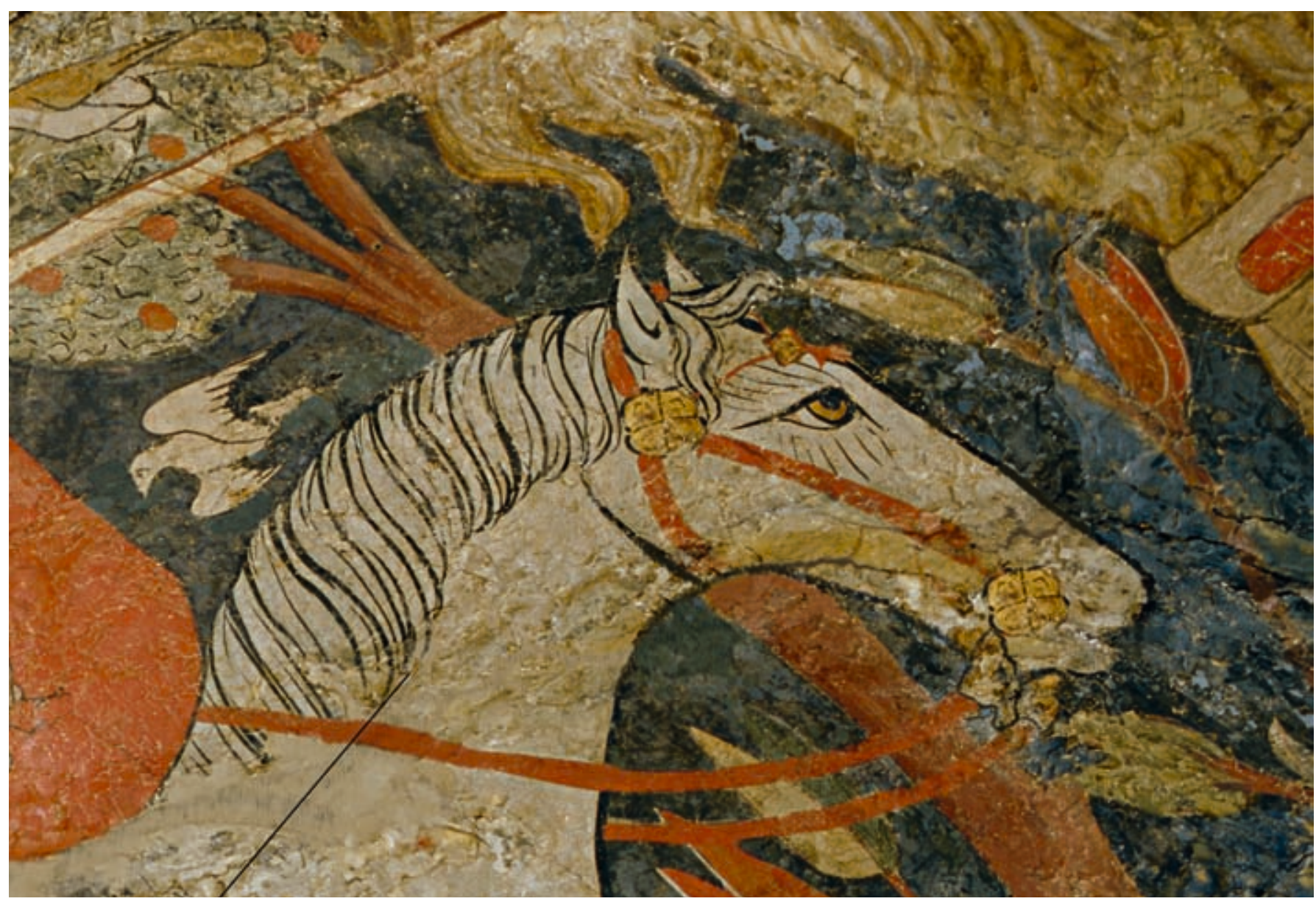

Reconstrucción hipotética del bocado del caballo 

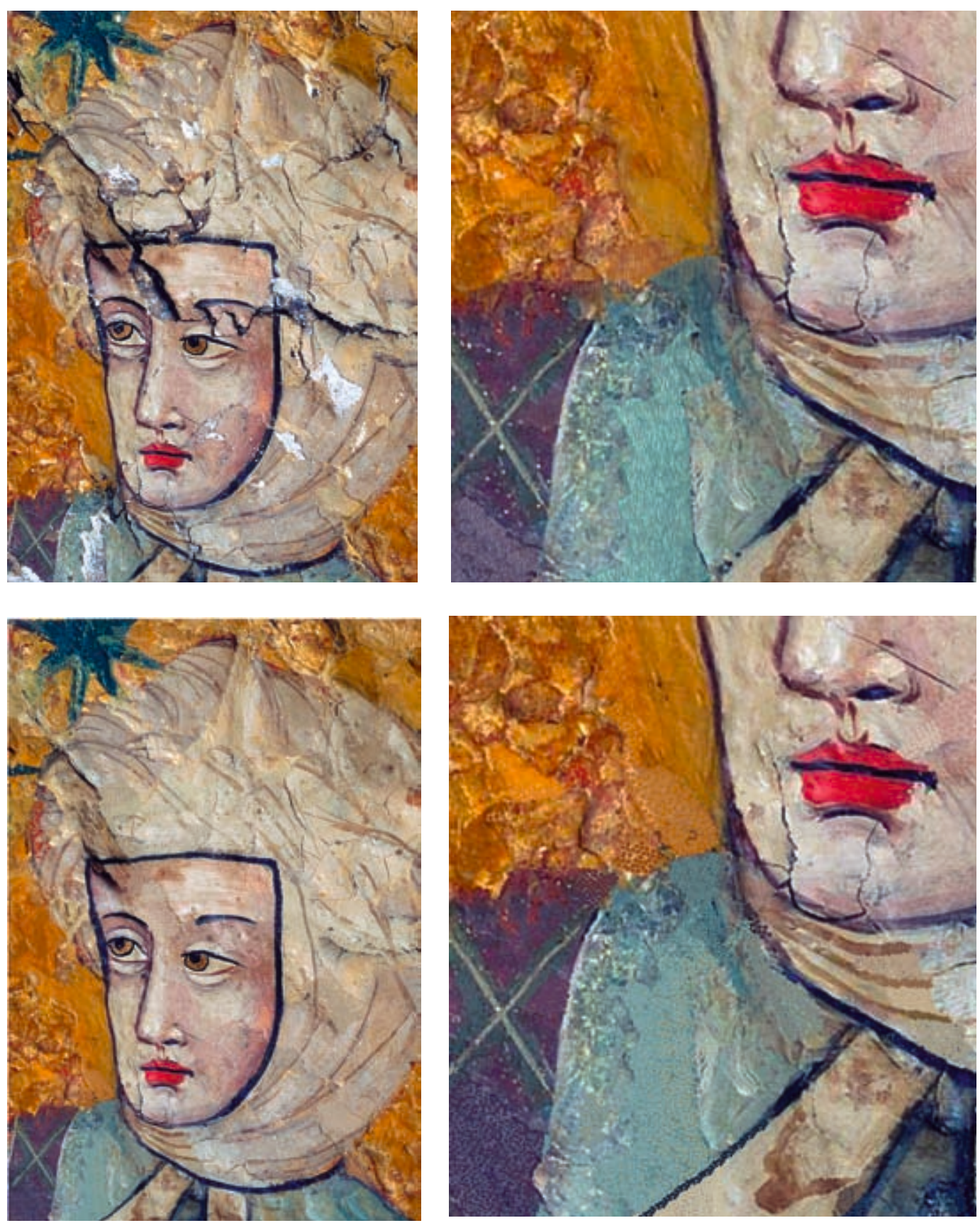

Resultado final de la reintegración virtual de lagunas en la cabeza del rey (Sala $\mathrm{n}^{\circ}$ 2) y detalles de

los sistemas realizados: rigatino,
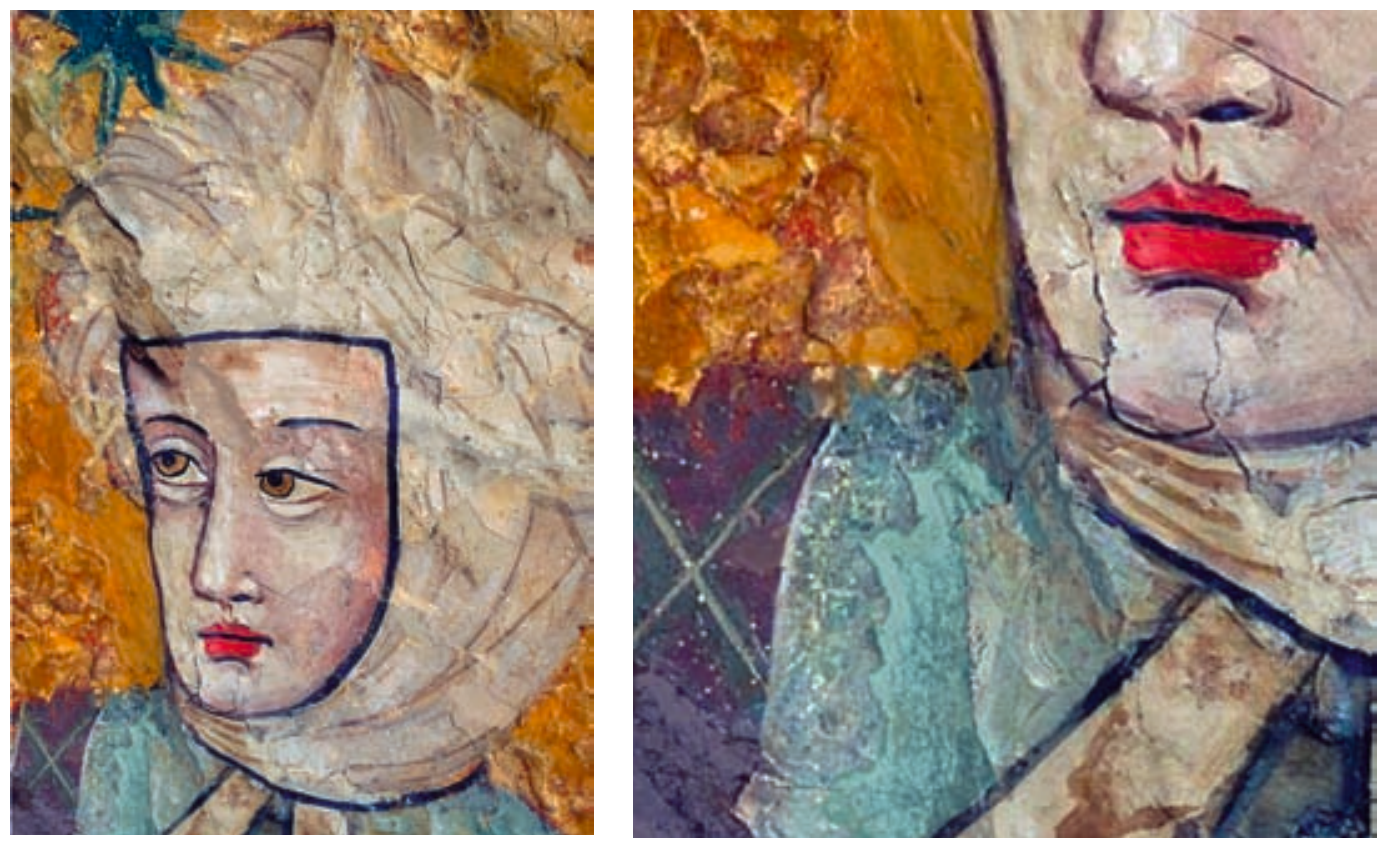


\section{Resultados, evaluación y discusión del método seguido}

El trabajo realizado en este proyecto se ha basado en el estudio de las reintegraciones virtuales de las imágenes sobre un detalle de la bóveda 1, en el que se representa la imagen de un caballo que presenta diferentes tipos de patologías, así como otro detalle de la bóveda 2, que representa el rostro del rey 4; ambas bóvedas se localizan en La Sala de los Reyes de la Alhambra de Granada. Los diferentes estudios de reintegración realizados han posibilitado la visión del estado de dichas áreas tras concluir el tratamiento de reintegración, en este caso virtual, de las lagunas. El resultado en esta fase de puesta a punto del método ha resultado totalmente satisfactorio, ya que aun siendo consciente de que la imagen final obtenida no se correspondería con la real de la obra intervenida, puesto que se parte de una imagen donde son evidentes alteraciones no tratadas, como levantamientos y deformaciones que desvirtúan la superficie, y de que los colores con los que se ha trabajado no son los reales, el método, y su posterior aplicación, se ha revelado útil de cara a definir la actuación, relativamente sencillo de manejar y aplicar sobre una obra dada y de rápida ejecución.

También se ha constatado que, además de ser un elemento útil a la hora de definir el sistema de reintegración que más se adecua a un determinado bien cultural, también puede ser útil en la reconstrucción de partes faltantes, ya que se puede simular hipótesis de trabajo a partir de la documentación existente sobre la obra y su posterior reconstrucción virtual con los distintos sistemas de reintegración que se establezcan a priori. En el caso que nos ocupa, se ha realizado una primera aproximación a este trabajo con el estudio efectuado sobre los caballos de las bóvedas no 1 y $n^{\circ} 3$, con objeto de poder abordar la reconstrucción de la boca y adorno del bocado que lleva el caballo del fragmento escogido de la bóveda 1.

El estudio y puesta a punto del método se ha llevado a cabo durante un periodo de cinco meses, tiempo que se ha revelado suficiente para el estudio realizado sobre dos detalles pertenecientes a las bóvedas no 1 y nº 2 .

Por otro lado, teniendo en cuenta que todo el proceso parte de una fotografía original de alta resolución realizada en formato tiff, que no está comprimida para que no se pierda información a la hora de trabajar sobre ella, lo que da un peso de partida considerable al archivo, y que el peso de este archivo va aumentando progresivamente a medida que se trabaja sobre la fotografía original con los diferentes procedimientos de reintegración y se añaden capas, resulta ventajoso usar un programa como el que hemos elegido para el proyecto porque los archivos generados, aunque aumentan progresivamente su peso, lo hace en un grado considerablemente menor que si usáramos otros programas informáticos similares, es decir, el peso final del archivo generado por CorelDraw 12 es mucho menor que el que pudiera generarse con otros programas afines.
Las imágenes finales de las reintegraciones virtuales realizadas se han guardado en tres tipos de formato: cdr, formato creado por Corel Draw 12, con objeto de disponer de toda la información de cada paso efectuado por si en un momento dado se necesita editar o continuar el trabajo a partir del momento en que se ha dado por definitivo; imágenes en formato tiff para poder disponer de imágenes de alta resolución que permita la reproducción de calidad, y por último, en formato $j p g$, formato de menor peso ya que la imagen se presenta comprimida y permite su manipulación, impresión y transmisión como imagen de trabajo de cierta calidad.

Somos conscientes de que el resultado obtenido ha estado condicionado por el estado de conservación de la pintura, ya que en cualquiera de los sistemas de reintegración virtual que se han ejecutado, siempre son perceptibles los levantamientos y deformaciones presentes, desvirtuando en parte el resultado y modificando su percepción final. Actualmente, los anversos de las tres pinturas se encuentran en fase de estudio y protegidos por un facing que impide cualquier tipo de acción hasta su restauración. Por ello, y aun cuando conocemos que la documentación de partida no es la ideal, puesto que toda la documentación de la que disponemos refleja un estado superficial derivado de las alteraciones existentes y que éstas interfieren en el resultado obtenido, nos ha parecido oportuno en esta fase de la investigación, poner a punto el método para, que en el momento que las condiciones sean óptimas, y podamos documentar e intervenir en sus anversos, pueda hacerse extensible a su conjunto.

No se ha pretendido con este trabajo solucionar el problema conservativo o de intervención en La Sala de los Reyes sino poner a punto un método de trabajo que permita aplicar la reintegración virtual de lagunas a la toma de decisión de intervenciones en casos complejos y únicos como el que nos ocupa.

En cuanto al método de reintegración virtual seguido para el estudio del tratamiento virtual de las reintegraciones en obras de arte, ha resultado apropiado para los fines que se persiguen en este tipo de trabajos de restauración porque nos ha permitido estudiar y trabajar sobre las obras de arte con una serie de herramientas que facilitan enormemente la labor que debe realizarse, $y$ anticipan los resultados finales sin ningún coste físico para la obra y sin tener que permanecer durante mucho tiempo in situ en la localización original de la obra.

\section{CONCLUSIONES}

La reintegración virtual de lagunas es un campo abierto por experimentar y trabajar, las posibilidades que ofrece son múltiples y muy interesantes, ya que su aplicación puede verdaderamente ayudar a la toma de decisión. Con este trabajo hemos constatado que es un método viable, y de gran utilidad en casos complejos donde los criterios de intervención que se definan puedan 

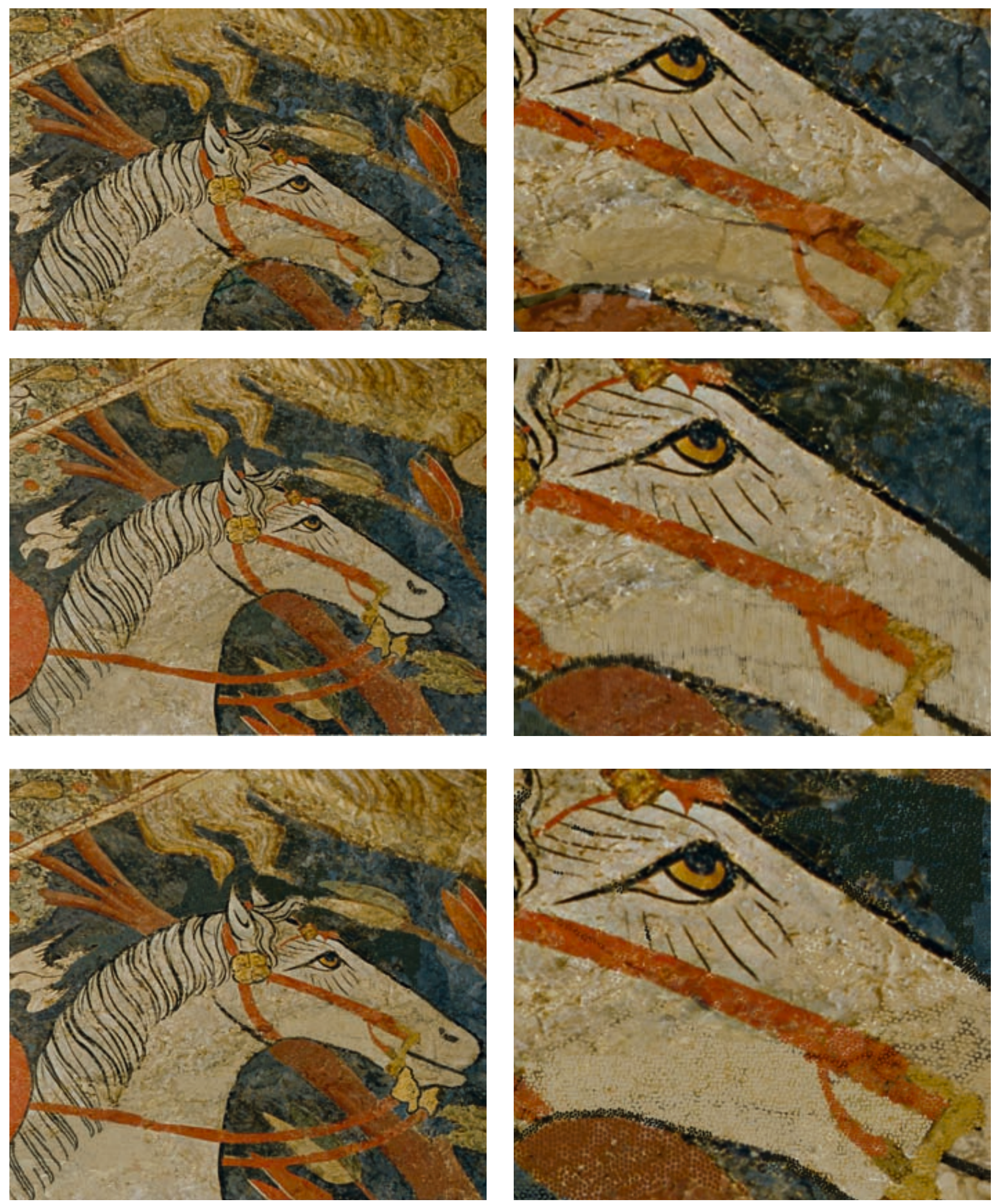

Resultado final de la reintegración virtual de lagunas en la cabeza del caballo (Sala $\mathrm{n}^{\circ}$ 1) y detalles de los sistemas

realizados: tinta plana, rigatino y puntillismo 
modificar sustancialmente las características y la percepción de la obra, y que implícitamente involucre a tratamientos dificiles y costosos como puede ser la reintegración de lagunas.

Su realización nos ha demostrado que puede ser factible $y$, una vez que se pone a punto el método, resulta cómodo y senciIlo, además se puede reproducir, grabar y difundir sin problemas por lo que la información puede estar en manos de las personas que se consideren oportunas de forma rápida y segura. Por lo demás, hasta su puesta en obra, la reintegración virtual de lagunas es completamente inocua puesto que los resultados pueden visionarse con facilidad sin necesidad de tocar la obra original, lo único que se demanda de ella es una buena documentación fotográfica de alta resolución.

Esta documentación constituirá una información visual básica de considerable interés para que la toma de decisión del criterio y del sistema de reintegración que se seleccione en una obra determinada venga avalado por una imagen visual de la obra acabada, sin necesidad de intervenir directamente sobre la obra real. Este hecho constituye sin duda una indudable ventaja a la hora de definir o articular la intervención que se propone facilitando el proceso de ejecución posterior y también su divulgación; puesto que se pueden realizar cuantas pruebas se precisen acerca de los diferentes tipos de reintegración, además de las posibilidades que plantea en un problema tan complejo, como lo es la reconstrucción de partes faltantes, ya que se pueden reconstruir virtualmente éstas en base a la información que se derive del estudio de documentos históricos, de copias precedentes, de imágenes de archivos o de estudio, etc.; todo ello para determinar el criterio y el sistema de reintegración más adecuado a cada situación o a cada bien cultural en función de sus exigencias conservativas y estéticas, que permita posteriormente su aplicación con garantías de éxito, y todo ello, de forma virtual y sin necesidad de tocar la obra original.

La restauración vive dentro de un sistema globalizado donde las nuevas tecnologias se están revelando como las herramientas necesarias e idóneas para realizar cierto tipo de labores. Cada vez más el pincel y la acuarela están dando paso a las herramientas tecnológicas, si bien, lejos de sustituir unas a otras, ambas pueden y deben ser perfectamente complementarias, con sólo perfilar adecuadamente sus ámbitos de aplicación. No cabe duda que, en el arranque de este siglo XXI, todo esto ya está empezando a ser una realidad. Y estamos sólo en el inicio. de Sevilla a través del Departamento de Pintura y la Consejería de Cultura (IAPH). Vanessa Martínez Calvo: Estancia de especialización de seis meses sobre tratamiento digitalizado de la imagen. La investigación se ha llevado a cabo en las dependencias del Centro de Intervención del IAPH bajo la dirección de Ma José González López, directora técnica del proyecto de intervención en las pinturas y bajo la dirección del Jefe de Centro de Intervención en el Patrimonio Histórico Lorenzo Pérez del Campo. ${ }^{2}$ Véase el proyecto desarrollado por el IAPH para las Pinturas de La Sala de los Reyes. Alhambra de Granada. Proyecto de intervención de urgencia. Primera fase: fijación preliminar y facing de protección ejecutado en 2006 (Sin publicar).

\section{Bibliografía}

AA.W. (1996) Recent progress in ink jet technologies / and II, versión CD ROM, Springfield, 1999

AROUILLO AVILÉS, D. (2000) La Limpieza Virtual. En Actas XIII Congreso de Conservación y Restauración de Bienes Culturales. Lleida: ICOM, Congreso de Conservación y Restauración de Bienes Culturales, 2000

BAIN, S. (2004) CorelDraw 12 (el libro oficial). Madrid: Anaya multimedia-Anaya interactiva, 2004

DE LA ROJA DE LA ROJA, J. M. (2004) Sistema de reintegración cromática asistido por medios transferibles obtenidos por procedimientos fotomecánicos. Aplicación en la restauración de pintura de caballete. Madrid: Universidad Complutense de Madrid, 2004

ESCRIG MORENO, M. J.; PUERTES TORRENT, C. (1994) Aplicaciones y reintegraciones informatizadas. En ESCALERA UREÑA, A.; PÉREZ GARCÍA, C. (coord.) X Congreso de Conservación y Restauración de Bienes Culturales: Cuenca, 29, 30 de septiembre, 1, 2 de octubre de 1994. Madrid: Ministerio de Cultura, Secretaría del Congreso de Conservación y Restauración de Bienes Culturales, 1994, pp. 175-179 ESCRIG MORENO, M. J.; PUERTES TORRENT, C. Arranque, Restauración y Reintegración informatizada de un Zócalo Mural de un Palacio Civil Islámico en Játiva (Valencia). En Actas XI Congreso de Conservación y Restauración de Bienes Culturales. Castellón: Diputación Provincial de Castellón, 1996

GONZÁLEZ MOZO, A. (1998) Tratamiento informático de la imagen en los procesos de documentación y reintegración en restauración de obras de arte. Madrid: Universidad Complutense, 1998

PAZ GONZÁLEZ, F. (2004) CorelDraw 12: ilustración, dibujo vectorial y maquetación de páginas (Manuales imprescindibles). Madrid: Anaya multimedia-Anaya interactiva, 2004

REGIDOR ROS, J. L. (2004) Estabilidad, protección y aceptación de las impresiones ink jet en procesos de creación y conservación de obras de arte. CD ROM, Valencia, 2004

ROLAND DG \& SCANVEC-AMIABLE (1999) La Impresión digital en Color. BarceIona: Roland Electronics de España SA, 1999

RUIZ DE ARCAUTE MARTíNEZ, E. (2002) Reconstitution des polychromies par ordinateur. Possibilités et limites. En La couleur et la pierre. Polychromie des portails gothiques. Actes du Colloque. Amiens 12-14 octubre 2000. Paris: Editions A. et J. Picard, 2002, pp. 259-265

ZAMARRO FLORES, E. (2007) La tecnología de inyección de tinta como herramienta para la práctica artística. Tesis doctoral (Domiciano Fernández Barrientos, director). Universidad Complutense de Madrid, 2007

\section{Notas}

${ }^{1}$ Esta actividad se ha desarrollado dentro de las actividades que para el proyecto de Intervención en las pinturas de La Sala de los Reyes ha promovido el IAPH:

Ma José González López: Contrato de investigación y asesoramiento técnico para la supervisión técnico-científica de la intervención la fuente del patio de los leones y en los reversos de las pinturas sobre cuero de "la sala de los reyes" de la Alhambra de Granada. Contrato de investigación (artículos 68/83 L.0.U.) suscrito entre la Universidad 